\title{
Psycho physical test in normal individual and diabetic patients with and without diabetic retinopathy: comparative study
}

\author{
Raghuwanshi $\mathbf{S}^{1}$, Kumar $\mathbf{R}^{2}$, Raghuwanshi $\mathrm{SK}^{3}$ \\ ${ }^{1}$ Dr. Sapna Raghuwanshi, Assistant Professor, ${ }^{2}$ Dr. Rashmi Kumar, Assistant Professor, above authors are affiliated with \\ Department of Ophthalmology, L. N. Medical College Bhopal, ${ }^{3}$ Dr. Shivkumar Raghuwanshi, Professor, Department of \\ ENT, L. N. Medical College Bhopal, MP, India.
}

Corresponding Author: Dr. Rashmi Kumar, Assistant Professor, Department of Ophthalmology, L. N. Medical College Bhopal. E-mail: rashmikumardr@gmail.com

\begin{abstract}
Purpose: To investigate the differentiating ability of psycho physical test which include contrast sensitivity function (CSF), dark adaptation (DA) and best corrected visual acuity (BCVA) in detecting functional losses in diabetic participants with and without retinopathy. Methods: In this cross-sectional study we examined 90 patients in L.N. Medical College and J.K Hospital, Kolar road, Bhopal between June to November 2017 including 60 diabetic patients (30 with retinopathy and 30 without retinopathy in fundus photography) with 30 control non-diabetic subjects matched for age and sex. The diabetic participants were sub grouped according to the level of retinopathy (EDTRS classification). CSF was examined by means of pelli robson chart in each eye; DA was assessed with photostress test and BCVA by Snellen chart. Results: When comparing visual performance of the right and left eyes of patients in each group, CSF was significantly lower in the diabetic eyes with retinopathy than in the normal eyes or the diabetic eyes without retinopathy. Comparing to control group, there was a statistically significant CSF loss in the diabetic eyes without retinopathy $(\mathrm{P}<0.05)$. The mean $\log$ MAR BCVA and DA abnormalities were significantly higher in the diabetic eyes with retinopathy than in the normal eyes or the diabetic eyes without retinopathy $(\mathrm{P}<0.001)$. There was no significant difference observed in mean log MAR BCVA and DA between those of diabetic eye with out retinopathy compared to the control group. Conclusion: There was significant difference observed in visual performance of those diabetics with retinopathy compared to those without. The findings also suggest that the appropriate combination of existing tests can be a useful method of improving screening accuracy in diabetic patients.
\end{abstract}

Keywords: Contrast Sensitivity, Best Corrected Visual Acuity, Diabetic Retinopathy

\section{Introduction}

India leads the world with the largest number of diabetic subjects and termed the "diabetes capital of the world [1]. India has 31.7 million diabetic subjects at present as per WHO estimates [2]. Diabetes has many manifestations in the eye. Diabetic Retinopathy (DR) is the most important causes of visual impairment in diabetes. Diabetic Retinopathy is present in $40 \%$ of people with diabetes and DR is the primary cause of blindness in working age adults and remains an unresolved therapeutic challenge[3, 4, 5]. Almost all patients will have some degree of retinopathy 15-20 years after diagnosis $[6,7,8]$. The incidence of DR has increased, with the increase in the life expectancy of diabetics. DR is a progressive disease predominantly

Manuscript received: $4^{\text {th }}$ February 2018

Reviewed: $14^{\text {th }}$ February 2018

Author Corrected: $20^{\text {th }}$ February 2018

Accepted for Publication $24^{\text {th }}$ February 2018 affecting the integrity of the microscopic vessels found in the retina. DR is broadly divided into two clinical stages: non proliferative and proliferative diabetic retinopathy (PDR). Non proliferative is marked by retinal vascular microaneurysms, while Increased capillary permeability (due to breakdown of the bloodretina barrier) and capillary closure leading to retinal ischemia precede the development of macular edema and new vessel formation (proliferations), the two main complications that may lead to sight-threatening DR. Unfortunately, symptoms in eye of DR occur when the disease is in an advanced stage and has already caused irreversible anatomical damage. Currently, the diagnosis of DR requires an eye examination with a careful fundus examination and fundus photography that documents the current state of the retina allowing a better follow up. Sometimes an optical coherence 


\section{Original Research Article}

tomography (OCT) examination (macular edema) or a fluorescein angiography (diagnostic classification and planning of a laser treatment) are required.

Visual deficits in diabetes mellitus can be demonstrated by psychophysical and electro physiological techniques. Psychophysical tests include visual acuity, contrast sensitivity, color vision, and dark adaptation test [9]. A number of data have shown that diabetes affects visual function prior to the development of any structural abnormalities detectable by ophthalmoscopy or even by fluorescein angiography [10-14]. Study of the changes in Best Corrected Visual Acuity (BCVA), Contrast Sensitivity Function (CSF) and color vision, Dark Adaptation (DA) during various stages of retinopathy may provide information about the real usefulness of these cost-effective screening diagnostic tools in diabetic patients. Various studies have shown that cost effective screening can reduce blind registration due to diabetes $[15,16,17,18$, .

BCVA is the most commonly used non-invasive indicator of visual function. BCVA testing involves the use of a chart containing rows of letters of decreasing sizes with in each row. Scores reflect the ability to discriminate individual letters of various sizes on the charts, reflecting the spatial resolution of the retina. It is widely recognized that VA is compromised by diabetic retinopathy and it is associated with age, duration of diabetes, severity of diabetic retinopathy, and presence of macular edema [19]. Common VA tests include the Snellen chart and the Early Treatment for Diabetic Retinopathy Study chart. The measure of BCVA was not sensitive enough approach to detect the early stages of DR and to distinguished between groups with diabetes but no retinopathy, early DR and non-diabetic controls [11,20].

CSF is defined as a measure of the amount of contrast between light and dark (monochrome or color) required recognizing a unique visual target and most of the visual tasks that people encounter daily require the detection of objects with low contrast. This test, therefore, correlates better than visual acuity to the real visual function [21,22]. Further more, CS has the advantage of being easy and quick to perform, inexpensive and relatively reproducible[23]. Some author also found that contrast sensitivity is more closely related to the degree of retinopathy compared with color vision.

DA can be defined as the change in sensitivity of the retina when moving from bright light to low illumination conditions. At low levels of light, the rod photoreceptors are primarily responsible for vision, while the cones are less active; this is referred to as scotopic vision. So the dark adaptation refers to the adjustments made within the retina to allow for scotopic vision. Dark adaptation can be measured by first allowing the retina to adapt to total darkness and then measuring the time taken for the retina to return to a specific threshold of sensitivity after photo bleaching with a bright flash of light.

It has been shown that patientswith the early stages of DR have a significantly extended time of dark adaptation compared to nondiabetic subjects, so this may be a sensitive marker of early DR [24]. So, early detection and appropriate treatment can significantly reduce vision loss in diabetic patients landing into its complications. In this study, we would like to explore the effect of diabetics on macular functions using psychophysical tests; which include visual acuity, contrast sensitivity, dark adaptation.

\section{Material and Methods}

The study was carried out at L N. Medical college and J.K Hospital, Kolar road, Bhopal between Junes to November 2017. This is a cross sectional observational study and the informed consent was being taken from the patients along with the proper approval from the ethical committee. All the diabetic patient attending ophthalmology OPD were included in the study. We tested three groups of individuals : two groups of diabetic patients with and without retinopathy and one group of healthy age and sex-matched control subjects (each one consisted of 30 subjects).

All enrolled subjects received complete ophthalmological examination including BCVA, slit-lamp biomicroscopy, intraocular pressure measurement, direct and indirect ophthalmoscopy and fundus photography.

All Control subjects were included in the study, if they showed normal ophthalmological examination.

Exclusion criteria for all enrolled subjects in the study were significant ocular disease beside DR including cataract, glaucoma, optic nerve disease, macular diseases and anterior segment diseasesand history of photocoagulation. In addition, all patients who had history of amblyopia that influence CS were also excluded. Patients with a family history andthose who are taking medications that affect CSF were also excluded. Classification of retinopathy was made using 


\section{Original Research Article}

fundus photography following mydriasis. Medical history including duration of diabetes, mode of control, fasting blood glucose level, hypertension, renal disease and history of ocular photocoagulation were recorded. Best corrected visual acuity; CSF test and DA test were performed on the three groups without any significant prior training.

BCVA- Visual acuity was measured using a Snellen chart monocularly with the appropriate optical correction at the viewing distance of $6 \mathrm{~m}[25]$.

Contrast sensitivity-Contrast sensitivity function (CSF) was assessed with pellirobsonchart[26]. This chart is a clinically reliable, quick and low-cost test to detect early retinopathic changes in diabetic patients and it provides a reliable measurement of low spatial frequency contrast sensitivity (0.5- 2 cycles). This test measures contrast sensitivity using large letters as targets (equivalent to 20/60 acuity). There are group of 3 letters and for each group of 3 letters, contrast is decreased from left to right and from the top to the bottom of the chart. The lowest contrast at which 2 or 3 of the letters in a group can be read determines a log contrast sensitivity score.

A score of 2.0 indicates normal contrast sensitivity (100 percent), while a score below 1.5 suggests sensitivity impairment. After initial demonstration to each subject, each eye was tested separately. The participants were instructed to sit $1 \mathrm{~m}$ from the chart with his or her correction if needed. Usuallywe occlude one eye. The participants were instructed to read the alphabets starting from left hand corner. When he fails to respond several seconds are given to him to retry and guess the alphabets. The scores of the test are recorded by the faintest triplets out of which at least 3 letters are correctly identified. The $\log$ CSF value of this triplet is given by the number of scoring pad nearest to the triplet, either on the left or right side.

DA- DA was assessed with photo stress test [27]. This is a simple clinical technique that can differentiate between retinal (macular) and postretinal (e.g.optic nerve) disease. This test involves exposing the eye to the light from the ophthal-moscope for $10 \mathrm{~s}$ and measuring the time taken for acuity to return to within one line of pre-bleach acuity. Participants with normal healthy macular function should be able to read line in the 50-60 s. Patients with a macular problem may have recovery times lasting 1.5 to $3 \mathrm{~min}$ or longer. After initial demonstration to each subject, each eye was tested separately. The participants were instructed to cover or occlude one eye. visualacuity of theuncovered eye is measured by by Snellen's optotypes. Afterthat, eye which is investigatedis subjected to a bright light from ophthalmoscope directed onto macula for $10 \mathrm{~s}$. Then, the subject is asked to read the line of letters just above his/her best line of acuity. The timing starts when the ophthalmoscope or penlight is removed. Photostress recovery time is measured. Then the same procedure isrepeated for the fellow eye.

For the purpose of analysis, the cases were categorized into three groups; Group-1 included cases of Diabetics with diabetic retinopathy, Group-2 included cases of Diabetics without diabetic retinopathy and Group-3 included control subjects.

Statistical methods- The efficacy variables included CS, BCVA and DA. For comparison of three groups together ANOVA test (Analysis of Variance) is used.To find out which of the two groups of the three differ we use post hoc test ( LSD).

\section{Results}

Ninety cases were included in the study. 30 cases were included in each group. As per table 1 the mean age in Group 1 , Group 2, and Group 3 was 64.53, 55.6, and 50.53 years, respectively. Sex ratio (Male: Female) in Group 1, Group 2, and Group 3 was 1.3:1, 1.5:1and1:1respectively [Table 1].

Table-1: Comparison of patients' baseline characteristics between Groups 1, 2, and 3*

\begin{tabular}{|c|c|c|c|}
\hline Mean & Group 1 & Group 2 & Group 3 \\
\hline Age & 64.53 & 55.6 & 50.53 \\
\hline Sex ratio ( M: F) & $1.3: 1$ & $1.5: 1$ & $1: 1$ \\
\hline
\end{tabular}

*Group-1 included cases of Diabetics with diabetic retinopathy, Group-2 included cases of Diabetics without diabetic retinopathy, and Group-3 included control subjects.

CSF- Mean $\log$ CSFof right eye of subjects in Group 1 was $1.11 \pm 0.55$, Group 2 was $1.43 \pm 0.45$ and in Group 3 was $1.80 \pm 0.27$. Mean CSF of left eye of subjects in Group 1 was $1.16 \pm 0.59$, Group 2 was $1.46 \pm 0.43$ and in Group 3 was 


\section{Original Research Article}

$1.81 \pm 0.27$. In right eye subjects of Group 1 had a significantly lower mean log CSF than those in Group 2 (P $=.005)$ and Group $3(\mathrm{P}=0.000)$ and subjects in Group 2 had a significantly lower meanlog CSF than those in Group 3 (P = 0.001). In left eye subjects of Group 1 had a significantly lower mean log CSF than those in Group $2(\mathrm{P}=.012)$ and Group $3(\mathrm{P}=0.000)$ and subjects in Group 2 had a significantly lower meanlog CSF than those in Group $3(\mathrm{P}=0.004)$ [Table 2]. In right eye subjects of Group 1 with $\mathrm{DM}>5$ years duration had a significantly lower mean log CSF than those subjects with $\mathrm{DM}<5$ years duration $(\mathrm{P}=0.03$ ). In left eye subjects of Group 1 with $\mathrm{DM}>5$ years duration had a significantly lower mean $\log \mathrm{CS}$ than those subjects with $\mathrm{DM}<5$ years duration $(\mathrm{P}=0.001)$ [Table 5]. Based on the duration of DM there was no significant difference in mean $\log$ CS in Group 2 in right eye and in left eye respectively (P $=0.814)(\mathrm{P}=0.902)$ [table 6].

Table-2: Comparison of patients 'contrast sensitivity function between Groups 1, 2, and 3*

\begin{tabular}{|c|c|c|c|c|c|c|}
\hline Eye & \multicolumn{2}{|c|}{ Mean log contrast sensitivity } & \multicolumn{3}{c|}{ P } \\
\hline & Group 1 & Group 2 & Group 3 & $\begin{array}{c}\text { Between } \\
\text { group 1 and 2 }\end{array}$ & $\begin{array}{c}\text { Between } \\
\text { group 1 and 3 }\end{array}$ & $\begin{array}{c}\text { Between } \\
\text { group 2 and 3 }\end{array}$ \\
\hline $\mathrm{Rt}$ & 1.11 & 1.43 & 1.80 & $.005^{* *}$ & $.000^{* *}$ & $.001^{* *}$ \\
\hline $\mathrm{Lt}$ & 1.16 & 1.46 & 1.81 & $.012^{* *}$ & $.000^{* *}$ & $.004 * *$ \\
\hline
\end{tabular}

* Group-1 included cases of Diabetics with diabetic retinopathy, Group-2 included cases of Diabetics without diabetic retinopathy, and Group-3 included control subjects.

**The mean difference is significant at 0.05 levels.

Table-3: Comparison of patients' Decimal equivalent BCVA between Groups 1, 2, and 3*

\begin{tabular}{|c|c|c|c|c|c|c|}
\hline Eye & \multicolumn{2}{|c|}{ Mean Decimal equivalent BCVA } & \multicolumn{3}{c|}{ P } \\
\hline & Group 1 & Group 2 & Group 3 & $\begin{array}{c}\text { Between } \\
\text { group 1 and 2 }\end{array}$ & $\begin{array}{c}\text { Between group } \\
\text { 1 and 3 }\end{array}$ & $\begin{array}{c}\text { Between } \\
\text { group 2 and 3 }\end{array}$ \\
\hline $\mathrm{Rt}$ & 0.66 & 0.85 & 0.91 & $0.006^{* *}$ & $.000^{* *}$ & .428 \\
\hline $\mathrm{Lt}$ & 0.65 & 0.82 & 0.94 & $.027^{* *}$ & $.000^{* *}$ & .116 \\
\hline
\end{tabular}

* Group-1 included cases of Diabetics with diabetic retinopathy, Group-2 included cases of Diabetics without diabetic retinopathy, and Group-3 included control subjects.

**The mean difference is significant at 0.05 levels.

Table-4: Comparison of patients DA time between Groups 1, 2, and 3*

\begin{tabular}{|c|c|c|c|c|c|c|}
\hline Eye & \multicolumn{3}{|c|}{ MeanDA } & \multicolumn{3}{c|}{ P } \\
\hline & Group 1 & Group 2 & Group 3 & $\begin{array}{c}\text { Between } \\
\text { group 1 and } \\
\mathbf{2}\end{array}$ & $\begin{array}{c}\text { Between } \\
\text { group 1 and } \\
\mathbf{3}\end{array}$ & $\begin{array}{c}\text { Between } \\
\text { group 2 and } \\
\mathbf{3}\end{array}$ \\
\hline $\mathrm{Rt}$ & 19.63 & 18.70 & 6.00 & .835 & $.003^{* *}$ & $.006^{* *}$ \\
\hline $\mathrm{Lt}$ & 20.47 & 18.12 & 7.07 & 583 & $.002^{* *}$ & $.009^{* *}$ \\
\hline
\end{tabular}

* Group-1 included cases of Diabetics with diabetic retinopathy, Group-2 included cases of Diabetics without diabetic retinopathy, and Group-3 included control subjects

**The mean difference is significant at 0.05 levels.

BCVA- Mean decimal equivalent BCVA of Right Eye of subjects in Group 1 was $0.66 \pm 0.31$, Group 2 was $0.85 \pm 0.25$ and in Group 3 was $0.91 \pm 0.23$. Mean decimal equivalent BCVA of Left Eye of subjects in Group 1 was $0.65 \pm 0.31$, Group 2 was $0.82 \pm 0.27$ and in Group 3 was $0.94 \pm 031$.In right Eye subjects of Group 1had a significantly high mean decimal equivalent BCVA than those in Group $2(\mathrm{P}=.006)$ and Group $3(\mathrm{P}=0.000)$ and there was no significant difference in mean decimal equivalent VA in Group 2 and Group $3(\mathrm{P}=0.428)$. In left eye subjects of Group 1had a significantly high mean decimal equivalent BCVA than those in Group $2(\mathrm{P}=.027)$ and Group $3(\mathrm{P}=0.000)$ and There was no significant difference in mean decimal equivalent VA in Group 2 and Group $3(\mathrm{P}=0.116)$ [ Table 3]. Based on 


\section{Original Research Article}

the duration of DM there was no significant difference in mean decimal equivalent BCVA in Group 1 in right eye and in left eye respectively $(\mathrm{P}=0.206)(\mathrm{P}=0.464)$ [Table 5]. Based on the duration of $\mathrm{DM}$ there was no significant difference in mean decimal equivalent BCVA in Group 2 in right eye and in left eye respectively $(\mathrm{P}=0.318)(\mathrm{P}=0.216)[$ Table 6].

Table-5: Comparison of different variable based on duration of diabetes in Group 1

\begin{tabular}{|c|c|c|c|}
\hline Variable & Duration Diabetes & $\mathbf{N}$ & p value \\
\hline \multirow[t]{2}{*}{ VA Rt } & $<5$ years & 15 & 0.206 \\
\hline & $>5$ years & 15 & \\
\hline \multirow[t]{2}{*}{ VA Lt } & $<5$ years & 15 & 0.464 \\
\hline & $>5$ years & 15 & \\
\hline \multirow[t]{2}{*}{ DA Rt } & $<5$ years & 15 & 0.609 \\
\hline & $>5$ years & 15 & \\
\hline \multirow[t]{2}{*}{ DA Lt } & $<5$ years & 15 & 0.798 \\
\hline & $>5$ years & 15 & \\
\hline \multirow[t]{2}{*}{ CS Rt } & $<5$ years & 15 & $0.033^{*}$ \\
\hline & $>5$ years & 15 & \\
\hline \multirow[t]{2}{*}{ CS Lt } & $<5$ years & 15 & $0.001 *$ \\
\hline & $>5$ years & 15 & \\
\hline
\end{tabular}

*The mean difference is significant at 0.05 levels.

Table-6: Comparison different variable based on duration of diabetes in Group 2

\begin{tabular}{|c|c|c|c|}
\hline Variable & Duration Diabetes & $\mathbf{N}$ & p value \\
\hline \multirow{2}{*}{ VA Rt } & $<5$ years & 15 & 0.318 \\
\cline { 2 - 4 } & $>5$ years & 15 & 0.216 \\
\hline \multirow{2}{*}{ VA Lt } & $<5$ years & 15 & 0.427 \\
\cline { 2 - 4 } & $>5$ years & 15 & \\
\hline \multirow{2}{*}{ DA Rt } & $<5$ years & 15 & 0.910 \\
\cline { 2 - 4 } & $>5$ years & 15 & 0.814 \\
\hline \multirow{2}{*}{ DA Lt } & $<5$ years & 15 & \\
\cline { 2 - 4 } & $>5$ years & 15 & 0.902 \\
\hline \multirow{2}{*}{ CS Rt } & $<5$ years & 15 & \\
\cline { 2 - 4 } & $>5$ years & 15 & \\
\hline \multirow{2}{*}{ CS Lt } & $<5$ years & 15 & \\
\cline { 2 - 4 } & $>5$ years & 15 & \\
\hline
\end{tabular}

*The mean difference is significant at 0.05 levels.

DA-Mean DA time of right eye of subjects in Group 1 was $19.63 \pm 24.76$, Group 2 was $18.70 \pm 16.44$ and in Group 3 was $0.6 \pm 4.03$. Mean DA time of Left Eye of subjects in Group 1 was $20.47 \pm 18.10$, Group 2 was $18.12 \pm 20.55$ and in Group 3 was 7.07 5.77. In right eye subjects ofGroup 1had a significantly high mean DA time than those in Group 3 ( $P$ $=.003)$ butthere was no significant difference in mean DA time in Group 1 and Group $2(\mathrm{P}=0.835)$ and subjects in Group 2 had a significantly high mean DA time than those in Group $3(\mathrm{P}=0.006)$. In left Eye subjects of Group 1had a significantly high mean DA time than those in Group $3(\mathrm{P}=.002)$ but There was no significant difference in mean DA time in Group 1 and Group $2(\mathrm{P}=0.583)$ and subjects in Group 2 had a significantly high mean DA time than those in Group $3(\mathrm{P}=0.009)$ [ Table 4].

Based on the duration of DM there was no significant difference in mean DA in Group 1 in right eye and in left eye respectively $(\mathrm{P}=0.609)(\mathrm{P}=0.798)$ [Table 5]. Based on the duration of DM there was no significant difference in mean Decimal equivalentVA in Group 2 in right eye and in left eye respectively $(\mathrm{P}=0.427)(\mathrm{P}=0.910)$ [Table 6]. 


\section{Original Research Article}

\section{Discussion}

CSF-It is a measure of the amount of contrast between light and dark (monochrome or color) required to detect or recognize a unique visual target [28]. Here is a marked debateabout the loss of CS in diabetic patients with and without retinopathy[29].In our study, in Diabetic patients with and without retinopathy, low mean $\log$ CSF was found in both eyes. Group 1 had a significantly lower mean log CSF than those in Group 2 and Group 3 and subjects in Group 2 had a significantly lower mean $\log$ CSF than those in Group 3. The present results confirm the findings of most other studies that a CSF loss is present in diabetic patients with and without retinopathy. Noticewala $\mathrm{V}$ et al reported that there is significant reduction in contrast sensitivity function in subjects with diabetes as compared to healthy individuals[30].

Heravian et al reported that those with retinopathy to the control group, mean CS differed significantly at all spatial frequencies. However when comparing the group of diabetics without retinopathy with controls, it was found significant difference at 12 and $18 \mathrm{cpd}$ in the left eye but for the right eye the differences were not significant [31]. Ghafour et al. found a significant difference between normals and diabetic patients without retinopathy as well as those with retinopathy [32]. Using a high contrast Bailey-Lovie chart and a Pelli-Robson chart in 20 type 2 diabetic patients and 24 control subjects, Stavrou and Wood found a significant loss of CS in patients with retinopathy compared with the control group [11]. Support for these finding is also reported by Beszédesová et al who used Sine Wave Contrast Test (SWCT) and Pelli-Robson test in diabetic patients with mild nonproliferative diabetic retinopathy (NPDR). They reported thatthere was a statistically significant difference of CS comparison to the control group, in spatial frequencies of 1.5, 6, 12, $18 \mathrm{cpd}$. They also found a significant difference of CS in spatial frequencies of 6,12 and $18 \mathrm{cpd}$ in diabetics with mild NPDR in comparing to diabetic without retinopathy [33]. Abrishami et al reported that the loss of CSF in diabetes has been variously attributed to retinal changes, but also to lens changes[34]. Risk factors for this loss of of CSF include advanced age, high systolic blood pressure, and nephropathy [35]. In our study we tried to exclude all factors that could apparently affect CS function. Yet we observed a significant CS loss in diabetic patients compared with normal subjects. Mackie and Walsh also reported a significant increase in the CS threshold, which was most marked in a diabetic group who had PDR, but was also elevated significantly in the diabetic group with background retinopathy when compared with patients with no retinopathy [36]. North et al also demonstrated abnormal CS at all spatial frequencies in a group of patients with background retinopathy [37]. Lobo et al and Lovestam-Adrian et al both demonstrated changes in CS that was related to the degree of retinopathy [38, 39]. These findings confirm our results that a CS loss is presented in diabetic group with and without retinopathy. Therefore, this test, correlates better than visual acuity to the real visual function [22]. The PelliRobson chart represents a simple, reliable method of measuring spatial contrast sensitivity that is compatible with clinical practice. Accordingly, we chose to use this fairly simple quick and inexpensive test to study our diabetic patients to see what we could learn about the association of contrast sensitivity measurement and diabetic status of patients.CS which is measured by the Pelli-Robson chart, revealed reduced performance in diabetic subjects without DR and subjects with early DR when compared to controls in several studies[21, 23].

Wong et al suggested that the reason for low CSF in diabetics with minimal to no retinopathy is not clear. Abnormal fluid accumulation in the retina or disturbance of neural function in the retina or the visual pathways by overloading of the aldose reductase system may theoretically be invoked as possible mechanisms [40]. CSF differences were detected in the absence of obvious signs of DR, suggesting greater sensitivity of this test.

BCVA- BCVA is the most widely used non-invasive test of visual function. It is widely recognized that BCVA is compromised by diabetic retinopathy and decrease BCVAis associated with age, duration of diabetes, severity of diabetic retinopathy, and presence of macular edema [19]. The measure of BCVA was not sensitive enough to distinguish between groups with diabetes but no retinopathy and diabetic subgroups [11]. Ismail et al [20]. reported a significant difference between BCVA scores in individuals with progressive DR and controls, and when comparing them to groups with diabetes and early DR and No significant difference was found when comparing the early DR group with non-diabetic control groups. Noticewala $\mathrm{V}$ et al reported that there is significant reduction in BCVA function in subjects with diabetes as compared to healthy individuals [30]. In this study Group 1 had a significantly high mean decimal equivalent BCVAthan 


\section{Original Research Article}

those in Group 2 and Group 3 and There was no significant difference in mean decimal equivalent BCVA in Group 2 and Group 3. Therefore, BCVA is significantly reduced as DR progresses, but may not be a sensitive enough approach to detect the early stages of DR. The result of our study corroborates with those of previous studies.

DA-Dark adaptation can be defined as the change in sensitivity of the retina when moving from bright light to low illumination conditions. At low levels of light, the rod photoreceptors are mainly responsible for vision, while the cones become less active; this is referred to as scotopic vision.

Therefore, dark adaptation refers to the adjustments made within the retina to allow for scotopic vision to occur. Jackson et al reported that humans with the early stages of DR have a significantly extended time of dark adaptation compared to nondiabetic subjects, so this may be a sensitive marker of early DR[24].

Holopigian et al. reported an elevated threshold of dark adaptation in subjects with DR [41]. In this study Group 1 had a significantly high mean DA time than those in Group 3 and subjects in Group 2 had a significantly high mean DA time than those in Group 3 but There was no significant difference in mean DA time in Group 1 and Group 2. The impact of diabetes on the differential neural activity in the dark-adapted retina is an important aspect of visual function that has been overlooked by many mechanistic studies in DR research.

\section{Conclusion}

There is a wealth of data showing that DR is a sight threatening disease where early and effective treatment has been shown to reduce significantly the incidence of blindness. There is evidence to suggest that components of vision, such as BCVA, DA and CSF are altered by diabetes. They are impaired before structural retinal abnormalities can be detected through ophthalmoscopy or fluorescein angiography.

This study shows the differentiating ability of these tests in screening of diabetic patients. However, in our study sample size was insufficient to subgroup patients according to the stage of DR and compares the statistical results of these groups. Thus, a further study with larger sample size is recommended. Practicality and patient acceptability are important aspects of any widely used screening test Moreover these psycho physical testsare in expensive, reproducible, non- invasive and affordable for any eye clinic. We need to evaluate the use of these diagnostic methods in everyday clinical practice to improve our approach to patient care and, above all, to achieve a secondary prevention (screening) itself.

Advantages of this study- In this study we found that diabetic patients with and without retinopathy had significantly more CS, DA and BCVA losses than controls of similar age and sex. These tests, which are simple and quick to perform, could complement the existing screening tests for retinopathy, providing additional information about visual function, specially its change over time.

Contribution by Author- Dr. Sapna and Dr. Rashmi have prepared the manuscript after doing various test of diabetic as well as in normal subjects. Dr. Sapna has been assisted by Dr. S. K. Raghuwanshi during preparation of manuscript.

\section{Funding: Nil, Conflict of interest: None. Permission of IRB: Yes}

\section{References}

1. Mohan V, Sandeep S, Deepa R, Shah B, Varghese C. Epidemiology of type 2 diabetes: Indianscenario. Indian J Med Res. 2007 Mar;125(3):217-30.

2. Wild S, Roglic G, Green A, Sicree R, King H. Globalprevalence of diabetes: estimates for the year 2000 and projections for 2030. Diabetes Care.2004 May; 27(5):1047-53.

3. Yau JW, Rogers SL, Kawasaki Ret al.Meta-Analysis for Eye Disease (META-EYE) Study Group. Global prevalence and majorrisk factors of diabetic retinopathy. Diabetes Care. 2012Mar;35(3):556-64. doi: 10. 2337 / dc11-1909. Epub2012Feb1.

4. Ding J, Wong TY. Currentepidemiology of diabetic retinopathy and diabeticmacular edema. Curr Diab Rep. 2012Aug; 12(4): 346-54. doi: 10.1007/s 11892-0120283-6.

5. Romero-Aroca P. Managing diabetic macular edema: the leading cause of diabetes blindness. World J Diabetes. 2011 Jun 15; 2(6): 98-104. Published online 2011 Jun 15. doi: 10.4239/wjd.v2.i6.98.

6. Klein R, Klein BE, Moss SE, Davis MD, DeMets DL. The Wis consin epidemiologic study of diabetic retinopathy. II. Prevalence and risk of diabetic retinopathy when age at diagnosis is less than 30years. Arch Ophthalmol.1984Apr;102(4):520-6. 


\section{Original Research Article}

7. Aiello LP, Gardner TW, King GL, Blankenship G, Cavallerano JD, Ferris III FL Klein R. Diabetic retinopathy. Diabetes Care 1998; 21(1): 143-156.

8. Orchard TJ, Dorman JS, Maser RE, Becker DJ, Drash AL, Ellis D, LaPorte RE, Kuller LH. Prevalence of complications in IDDM by sex and duration. Pittsburgh Epidemiology of Diabetes Complications StudyII. Diabetes. 1990 Sep; 39(9):1116-24.

9. Frost-Larsen K, Larsen HW. Nyctometry - a new screening method for selection of patients with simpledia betic retinopathy who are at risk of developing prolife rative retinopathy. Results of a 3year follow-up. ActaOphthalmol (Copenh). 1983 Jun;61 (3): 353-61.

10. A Paul Chous, 1 Stuart P Richer, 2 Jeffry D Gerson, 3 Renu A Kowluru4. The Diabetes Visual Function Supplement Study (DiVFuSS). BJO Online First, published on June 18, 2015 as 10.1136/bjophthalmol2014306534.

11. Stavrou EP, Wood JM. Lettercontrast sensitivity changes in early diabetic retinopathy. Clin Exp Optom. 2003 May;86(3):152-6.

12. Olafsdóttir E, Stefánsson E. Biennial eye screening in patients with diabetes without retinopathy: 10-year experience. Br J Ophthalmol. 2007 Dec; 91 (12):1599601. Epub 2007 Jul 12.

13. Moloney J, Drury MI. Retinopathy and retinalfunction in insulin-dependent diabetes mellitus. Br J Ophthalmol. 1982 Dec; 66 (12):759-61.

14. Jackson GR, Barber AJ. Visual dysfunction associated with diabetic retinopathy. Curr Diab Rep. 2010 Oct; 10(5): 380-4. doi: 10.1007/s11892-0100132-4.

15. Beszédesová N, Budinská E, Skorkovská S. [Functional integrity of neural retina in 2. type diabetics]. Cesk Slov Oftalmol. 2009 Jul; 65 (4): 124-30.

16. Pomerance GN, Evans DW. Test-retest reliability of the CSV-1000 contrasttest and its relationship to glaucoma therapy. Invest Ophthalmol Vis Sci. 1994 Aug; 35(9):3357-61.

17. Scanlon PH, Foy C, Chen FK. Visual acuity measurement and ocular co-morbidity in diabetic retinopathy screening. Br J Ophthalmol. 2008 Jun;92 (6): 775-8. doi: 10.1136/bjo.2007.128561. Epub 2008 Mar 20.
18. Woods RL, Wood JM. The role of contrast sensitivity charts and contrast letter charts in clinical practice. Clin Exp Optom1995;78:2:43-57.

19. Moss SE, Klein R, Klein BE. The incidence of vision lossin adiabetic population. Ophthal-mology. 1988 Oct;95(10):1340-8.

20. Ismail GM, Whitaker D. Early detection of changes in visual function in diabetes mellitus. Ophthalmic Physiol Opt.1998Jan;18(1):3-12.

21. Sokol S, Moskowitz A, Skarf B, Evans R, Molitch M, Senior B. Contrast sensitivity in diabetics with and without background retinopathy. Arch Ophthalmol. 1985 Jan; 103 (1): 51-4.

22. Shaili Misra, ${ }^{1}$ Sandeep Saxena, Poonam Kishore, ${ }^{1}$ Shashi K. Bhasker, ${ }^{1}$ Arvind Misra, ${ }^{2}$ and Carsten H. Meyer $^{3}$, Association of contrast sensitivity with Log MAR visual acuity and glycosylated hemoglobin in non-insulin dependent diabetes mellitus, J Ocul Biol Dis Infor. 2010 Jun; 3(2): 60-63. Published online 2010 Nov 3. doi: 10.1007/s12177-010-9056-0.

23. Della Sala S, Bertoni G, Somazzi L, Stubbe F, Wilkins AJ. Impairedcontrast sensitivity in diabetic patients with and without retinopathy: a new technique for rapid assessment. Br J Ophthalmol. 1985 Feb;69 (2): 136-42.

24. Jackson GR, Scott IU, Quillen DA, Walter LE, Gardner TW. Innerretinal visual dysfunction is a sensitive marker of non-prolife rative diabetic retinopathy. Br J Ophthalmol. 2012 May; 96 (5):699703. doi: 10. 1136/bjophthalmol-2011-300467. Epub 2011 Dec 15.

25. Marsden J, Stevens S, Ebri A. How to measure distancevisual acuity. Community Eye Health. 2014; 27(85):16.

26. Pelli, D. G., Robson, J. G., \& Wilkins, A. J. The design of a new letter chart for measuring contrast sensitivity. Clinical Vision Sciences, (1988). 2(3), 187-199).

27. Lavingia B. Photostress test. Indian J Ophthalmol. 1983 May; 31(3):183.

28. Di Leo MA, Caputo S, Falsini B, Porciatti V, Minnella A, Greco AV, Ghirlanda G. Nonselectiveloss of contrast sensitivity in visualsystemtesting in early type I diabetes. Diabetes Care. 1992 May; 15(5): 620-5. 


\section{Original Research Article}

29. Javitt JC, Canner JK, Frank RG, Steinwachs DM, Sommer A. Detecting and treatingretinopathy in patients with type I diabetes mellitus. A health policy model. Ophthalmology. 1990 Apr; 97 (4): 483-94; discussion 494-5.

30. Noticewala V, Manisha Shastri, A study of contrast sensitivity changes in normal individual and diabetic patients with and without diabetic retinopathy, Int J Res Med Sci. 2017 Nov;5(11):4840-4845.

31. JavadHeravian, PhD1 - Naser Shoeibi, MD2 • Abbas Azimi, PhD1 - Shayesteh Yasini, MSc3 Hadi Ostadi Moghaddam, PhD1 - Abbas Ali Yekta, PhD1 • Habibollah Esmaily, PhD4 Evaluation of Contrast Sensitivity, Color Vision and Visual Acuity in Patients with and without Diabetes, Iranian Journal of Ophthalmology 2010; 22 (3):33-40 (C) 2010 by the Iranian Society of Ophthalmology

32. Ghafour M, Foulds WS, Allan D, Mc Clure F. Contrast sensitivity in diabetic subjects with and without retinopathy. Br JOphthalmol 1982; 66: 492-5.

33. Beszédesová N, Budinská E, Skorkovská S. [Functional integrity of neural retina in 2 . type diabetics]. Cesk Slov Oftalmol. 2009 Jul; 65(4):124-30.

34. Abrishami M, Heravian J, Derakhshan A, Mousavi M, Banaee T, Daneshvar R, Moghaddam HO. Abnormal Cambrid gelow-contrast grating sensitivity results associated with diabetic retinopathy as a potential screening tool. East Mediterr Health J. 2007 Jul-Aug; 13(4):810-8.

35. Dosso AA, Bonvin ER, Morel Y, Golay A, Assal JP, Leuenberger PM. Risk factors associated with contrast sensitivity loss in diabetic patients. Graefes Arch ClinExpOphthalmol 1996 May; 234(5):3005.

36. Mackie SW, Walsh G. Contrast and glare sensitivity in diabetic patients with and without panretinal photocogulation. Ophthalmic Physiol Opt 1998 Mar; 18(2): 173-81.

37. North RV, Farrell U, Banford D, Jones C, Gregory JW, Butler G, Owens DR. Visual function in young DDM patients over 8 years of age. A 4-year longitudinal study. Diabetes Care. 1997 Nov; 20 (11): 1724-30.

38. Lobo CL, Bernardes RC, Figueira JP, de Abreu JR, Cunha-VazJGl. Three-year follow-up study of bloodretinal barrier and retinal thickness alterations in patients with type 2 diabetes mellitus and mild non prolife rative diabetic retinopathy. Arch Ophthalmol 2004; 122(2):211-7. 24.

39. Lövestam-Adrian M, Svendenius N, Agardh E. Contrast sensitivity and visual recovery time in diabetic patient streated with panretinal photocoagulation. Acta Ophthalmol Scand.2000Dec;78(6):672-6.

40. Wong R, Khan J, Adewoyin T, Sivaprasad S, Arden GB, Chong V. The ChromaTest, a digitalcolorcontrast sensitivity analyzer, for diabetic maculopathy: a pilot study. BMC Ophthalmol.2008 Aug 17;8:15. doi: 10. 1186/1471-2415-8-15.

41. Holopigian K, Greenstein VC, Seiple W, Hood DC, Carr RE. Evidence for photoreceptorchanges in patients with diabetic retinopathy. Invest Ophthalmol Vis Sci. 1997Oct; 38(11):2355-65.

\section{How to cite this article?}

Raghuwanshi S, Kumar R, Raghuwanshi SK. Psycho physical test in normal individual and diabetic patients with and without diabetic retinopathy: comparative study. Int J Med Res Rev 2018;6 (02):93-101. doi:10.17511/ijmrr. 2018.i02.05. 